\title{
A review of trends in scientific coverage of water governance in South Africa and what this means for agenda-setting of public investment in water governance R\&D
}

\author{
Inga Jacobs-Mata', Patience Mukuyu' ${ }^{1}$ and John Dini² \\ 'International Water Management Institute (IWMI), 141 Cresswell Street, Weavind Park, Pretoria, 0184, South Africa \\ ${ }^{2}$ Water Research Commission, 18 Hilden Rd, Lynnwood Manor, Pretoria, 0081, South Africa
}

A review of global trends in water governance reveals a paradigm dominated by political and institutional change which becomes increasingly aligned with global shifts towards sustainability and also a rapid decline in the hydraulic mission. Closely aligned to these trends, but distinct in its own trajectory, South Africa's water governance dynamics have evolved through a period of considerable socio-political change marked by inequitable resource allocation and water scarcity. This paper presents the results of a review of water governance research and development (R\&D) trends in South Africa, aimed at informing the national funding agency - the Water Research Commission (WRC) - in its agenda-setting process for future water governance research. Through a bibliometric analysis, a data-mining exercise, and stakeholder consultations, this paper distils four key areas of focus for the future of water governance research in South Africa: (i) that future water governance research needs to be more needs-based, solution-oriented and embedded within real-life contexts; (ii) the need for a paradigm shift in water governance research to a constructive, adaptive and rapid response research agenda in an environment of increasing change and uncertainty; (iii) the need for the enabling environment to be strengthened, including acknowledgement of the role of individuals as agents of change, and the role of WRC in establishing a community of practice for water governance experts that can respond to issues with agility; and (iv) a consolidation of fragmented project-based knowledge to a programmatic approach that builds the pipeline of expertise in the water governance R\&D domain.

\section{INTRODUCTION}

Water governance is the overarching and broad domain that people point at when water systems fail the world over - 'the water crisis is a crisis of governance' (GWP, 2002; OECD, 2011), and yet it is not so easily defined. A widely accepted, albeit very broad, definition of this term is provided by the Global Water Partnership (GWP), that defines it as 'the range of political, social, economic and administrative systems that are in place to develop and manage water resources, and the delivery of water services, at different levels of society' (GWP, 2002 cited in Rogers and Hall, 2003 p. 7). Simply put, water governance is the set of systems that control decision-making with regard to water resource development and management.

Water governance is therefore much more about the way in which decisions are made (i.e., how, by whom, and under what conditions decisions are made) than about the decisions themselves (Moench et al., 2003). Most often it is about the political choices about where water should flow; the norms, rules and laws on which such choices should be based; who is best able or qualified to decide this; and about the kind of societal future such choices support (Zwarteveen et al., 2017). It is as much about the formal institutions and processes by which authority is exercised as it is about the informal processes and institutions doing the same.

In addition, the way in which water governance is approached and applied in academic and also decision-making circles is often more about what water governance should be as opposed to what it actually is (Zwarteveen et al., 2017). For example, the concept of 'good governance' adopted by funders in their lending policies to developing countries, has come to be associated with the promotion of transparency, accountability, and integrity, and has become the 'neutral' title for a distinct political reform agenda (Lautze et al., 2011; Colebatch, 2014; Zwarteveen et al., 2017). This agenda has merged New Public Management principles with support for liberal democracy (Rhodes, 1996; Zwarteveen et al., 2017) through the free market economy; the privatization of public enterprises; the movement towards a leaner civil service; the introduction of budgetary discipline; the decentralization of administration and the greater reliance on non-governmental organizations (Zwarteveen et al., 2017). Most notably, this reform agenda has also advocated for the creation of markets or quasimarket mechanisms for regulating water resources or water rights with the assumption that it would improve the productivity of water uses and address the challenges of environmental degradation (Boelens et al., 2005; Bakker, 2008; Ahlers and Zwarteveen, 2009; Zwarteveen et al., 2017).

More recently, normative approaches have become more nuanced. As noted by the Water Governance Facility (WGF), 'governance should mainly be perceived as a neutral term. What is good for some can be bad for others' (WGF, 2016 p. 1). These trends reflect the notion that improved governance is path-dependent and needs to be linked to particular development goals in society, such as water services and sanitation for all, equitable reallocation of water between users, or any other goals such as food and energy for all, or conservation/restoration of ecosystems. It therefore refers not only to

\section{CORRESPONDENCE}

Inga Jacobs-Mata

\section{EMAIL}

i.jacobs-mata@cgiar.org

\section{DATES}

Received: 22 June 2020

Accepted: 16 January 2021

\section{KEYWORDS}

water governance

bibliometrics

water resource management

South Africa

$R \& D$

agenda-setting

\section{COPYRIGHT}

(c) The Author(s)

Published under a Creative

Commons Attribution 4.0

International Licence

(CC BY 4.0) 
the state of government, but to the overall health of society and to civil society and the private sector, and where development takes place within different constellations of these three entities. The Organisation for Economic Co-operation and Development (OECD) Principles on Water Governance are a good example of this, providing a framework to analyse water governance systems. To date, they have been endorsed by $170+$ stakeholder groups or governments - 'Coping with future water challenges raises not only the question of 'what to do?' but also 'who does what?', 'why?', 'at which level of government?' and 'how?'. Policy responses will only be viable if they are coherent, if stakeholders are properly engaged, if well-designed regulatory frameworks are in place, if there is adequate and accessible information, and if there is sufficient capacity, integrity and transparency' (OECD, 2015 p. 1).

These conceptualisations have also reflected several historical trends over time. Situating this work in a broader (international) context, this review acknowledges these global trends and normative conceptualisations. The term itself marks a change in policy emphasis from infrastructure to the organizational, financial, and institutional arrangements needed to regulate and order flows of water - a shift that came about in the 1980s to 1990s (Batchelor, 2006; Zwarteveen et al., 2017). But, as a concept, it has only recently been used in the water sector (Franks and Cleaver, 2007), making its appearance in the Second World Forum on Water held in The Hague in 2000 (Rogers and Hall, 2003). Later, the WGF, when it was established in 2005 out of a partnership between the UNDP and the Stockholm International Water Institute (SIWI), provided a more thorough and specific definition that includes those essential elements that water governance should address, including principles such as 'equity and efficiency in water resource and services allocation and distribution... [and] balances water use between socio-economic activities and ecosystems', demanding the 'clarification of the roles and responsibilities of government, civil society and the private sector in relation to water resources and services' (WGF, 2016; 2020).

This paper examines how these global shifts have played out in the context of water governance research and development (R\&D) in South Africa. Many aspects of water governance in South Africa have changed fundamentally since the end of apartheid and the transition to a new constitutional order following the first democratic elections in 1994. Yet, despite the major overhaul of water policy and law that characterised the second half of the 1990s, substantial obstacles continue to prevent the full realisation of the aspirations articulated over 20 years ago. It is thus important to understand the $\mathrm{R} \& \mathrm{D}$ response to these changes and their accompanying challenges over the past two decades. More importantly, what has been the impact of the $\mathrm{R} \& \mathrm{D}$ response on the ability to address some of the major water governance challenges unique to South Africa? And what does this reflection suggest for the construction of a future $R \& D$ agenda on water governance in South Africa?

The aims of this paper are therefore to summarise the key findings of a review of current knowledge on water governance in or relevant to South Africa, conducted through a commissioned WRC-funded research project (Jacobs-Mata and Mukuyu, 2020), and articulate recommendations for a future $R \& D$ agenda on water governance. In order to facilitate the production of relevant water research that speaks to the needs of a country we first had to take stock of the current state of knowledge, its research inputs (budget expenditure, for example), outputs (publications and patents, for example) and areas of focus, in order to determine critical gaps in R\&D and capacity. We provide an overview of peer-reviewed research generated on water governance for the South African context through a bibliometric analysis and a datamining exercise of the water governance funding portfolio of the
WRC, the national funding agency for water research in South Africa. This review, together with feedback from stakeholders, informs and forms part of the process for agenda setting regarding the future of water governance research in South Africa. The need for a national water governance research agenda has been articulated by academics and policy-makers alike as the evidencebased solution to inform water policy and ultimately address the complex water challenges we are faced with today.

\section{An overview of mega-trend water governance R\&D literature}

A growing body of research has observed key trends, narratives and paradigm shifts that have characterised water governance over time. At the global level, Allan (2005) refers to the transition of five water management paradigms, each with its own distinct focus and function. He calls the first of the five paradigms 'the premodern paradigm, which spanned from 1850 to the beginning of the $20^{\text {th }}$ century, and which was dominated by a general increase in water supply and use. During this period, the world saw great engineering ingenuity. The second paradigm, occurring from the early to late $20^{\text {th }}$ century, was characterised by industrial modernity and again featured an increase in activity in the hydraulic mission. This period also saw an increase in water demand as a result of agricultural activity shifting from subsistence to commercial, followed by further demands on water resources as a result of the rapid increase in industrial activity.

The third paradigm in Allan's (2005) framework, present only in industrialised nations from the 1960s onwards, shows a shift towards sustainable resource management and a concerted effort to redress the damage done by previous paradigms (Allan, 2005). The fourth, gaining currency in the early 1990s to the 2000s, is characterised by a period of economic expansion (particularly in the North) and by smart economic decisions that offer several environmental advantages, but is also characterised by a general decline in the hydraulic mission. This paradigm was inspired by economists, who began to advocate to water users in the North the economic value of water and its importance as a scarce economic input. Finally, the fifth paradigm, taking shape from the early 2000s, is based on the notion that water allocation and management are political processes. It is also dominated by political and institutional change which becomes increasingly aligned with global shifts towards sustainability and also a rapid decline in the hydraulic mission (Allan, 2005).

There are elements within Allan's (2005) management paradigms that mirror similar developments in water resource management in South Africa. Both Siebrits et al. (2014) and Tempelhoff (2018) corroborate Allan's (2005) global paradigm shifts by observing similar trends in water resources in South Africa. Tempelhoff (2018) takes a historical perspective of water governance in South Africa that mirrors these global trends. He argues that from 1912 to 1947 water governance focused on the realisation of a foodagricultural hydraulic mission, i.e., developing the country's water resources primarily for the farming sector - specifically the irrigation farming sector - to provide food supplies for local consumption and export. He refers to the period between 1947 and 1994 as the second phase, i.e. the energy-industrial hydraulic mission, a period that saw the state backing industrial development by securing sufficient water supplies and also by the generation of electricity. 'It was a period notable for the deterministic style of engineering and technology that flourished at an exceptional rate, with significant scientific breakthroughs. For the greater part of the period (especially 1960 to 1990) South Africa was politically isolated from the international community and the key water sector developments commonly trending internationally' (Tempelhoff, 2018 p. 9). 
The third (and current) phase started in 1992, and is referred to as a social ecological hydraulic mission. 'The dominant paradigm of the 1990s was the creation of a non-racial democracy in South Africa. Along with a new environmental awareness came a greater awareness of government's social responsibility to secure good drinking water and proper sanitation for all the people resident in the state. From 1994, this frame of mind paved the way for a greater governmental concern for ordinary people, especially those who had been previously disadvantaged by the apartheid era policies of the state. The principle of sustainability ensured that environmental awareness would form part of the legislation related to the country's water resources and governance' (Tempelhoff, 2018 p. 10). However, over the long-term, IWRM appeared difficult to implement and issues of water privatisation and neo-liberal economic policies asserted their influence (Tempelhoff, 2018).

In a study of paradigm shifts, Siebrits et al. (2014) refer to two major paradigms and one significant transition period. The first paradigm, most dominant from 1977 to 1991, emphasises the hydraulic mission which focused on securing supply and understanding basic natural systems. Research published in this period is dominated by engineering and laboratory-related disciplines, and characterised by efforts to ensure water supply, drainage and the development of the sewered city. The next 10 years (1992-2001) see a transitional period evidenced by water quality constraints and fields of management and planning. 'This paradigm is in response to changes in water deficits and a focus on end-use efficiency' (Siebrits et al., 2014 p. 8). A second paradigm shift occurs with a 'new social contract' around water emerging in a period of democratic transition, growing environmentalism and a rise of civil society activism. The need to plan, model catchments and include other disciplines (enter inter/multi/and later transdisciplinarity) becomes evident in the research environment.

Our study sought to compare the results of the above-mentioned studies with that of a more recent review of water governance R\&D in South Africa, including research up to 2019.

\section{METHODS}

To inform the WRC agenda-setting process for water governance research, three methods were used: (i) a bibliometric analysis of research outputs published, (ii) a data-mining exercise of the WRC's water governance portfolio, and (iii) a consultative stakeholder engagement process.

\section{Bibliometric assessment}

An analysis of the state of water governance R\&D in South Africa was conducted using bibliometric methods. Typically, bibliometric studies have been used (i) to measure, classify, and describe the nature of scientific outputs; (ii) to understand the dissemination of knowledge; (iii) to identify the theoretical and practical impact of academic studies; (iv) to understand the behaviour of individual researchers, research teams, and institutions; (v) to explore the nature of scientific outlets; (vi) to determine the most efficient allocation of resources to maximize research output and impact; and (vii) to propose recommendations for research policy development (Serenko, 2013). These studies have grown in prominence, particularly because of their use in the evaluation and management of research performance by governments and their science-based and funding agencies, whether at the level of the researcher, research group, institution or journal.

Despite its use in this study, the limitations of bibliometric methods are important to note. The first well-acknowledged limitation is the emphasis it places on peer-reviewed journal articles, that by nature omits the critically important role and impact of grey literature (including books, social media, etc.), particularly for social science and humanities disciplines that tend to make more use of books and other outputs to communicate research findings (Mingers and Leydesdorff, 2015). Although it is standard practice in most bibliometric studies to focus exclusively on articles in peerreviewed journals, the objectives of this study required a broader range of publications. The study set out to catalogue and analyse current published knowledge on water governance in or relevant to South Africa, to inform the process of agenda setting for future public investment in water governance research. This required the application of bibliometric and other techniques to a broader set of published literature, including a specific emphasis on relevant research reports published by the WRC and other grey literature.

Scopus, one of the largest abstract and citation databases of peerreviewed literature, was used as the basis for the bibliometric analysis and is commonly used in similar analyses (Özerol et al., 2018; DuránSánchez et al., 2019; Olagunju et al., 2019). In terms of the selection criteria, the search included both open-access and other access types from 1990 to 2019, identifying a total of 592 publications. However, after screening the initial dataset, the dataset was filtered for South Africa-specific publications, and non-governance publications were removed. The revised dataset included 511 publications, of which 92 were open access and 419 were other access types. A range of document types were included through an advanced search, with the large majority of documents in the dataset being peer-reviewed journal articles (73\%) as shown in Fig. 1. The following keywords were used in the Scopus Boolean search: (i) water govern* and South Africa; (ii) water polic* and South Africa; (iii) water law and South Africa; (iv) IWRM and South Africa; (v) water regulat* and South Africa; and (vi) catchment manage* and South Africa.

These search terms were consistent with the definition of water governance used in this project - the political, social, economic and administrative systems in place that influence water's use and management, including who gets what water, when and how, and who has the right to water and related services, and their benefits (Allan, 2001; WGF, 2020). In addition to the primary keywords used, a total of 150 secondary keywords were found in the document titles and abstracts of the dataset. The complete dataset was then analysed for: (i) the number of publications produced (e.g., the number of water governance publications identified per year, top publishing institutions, top publishing authors, and subject areas covered by the research); and (ii) the influence it had (e.g. most influential publications in terms of their number of citations, and the top funders of water governance R\&D). The identification of top publishing authors and institutions encompassed those based within South Africa and internationally, as long as they have published on water governance in South Africa. This was considered important in order to provide a complete picture of who has shaped, and is currently shaping, the knowledge base on water governance in South Africa, to better understand the community of practice (both local and international).

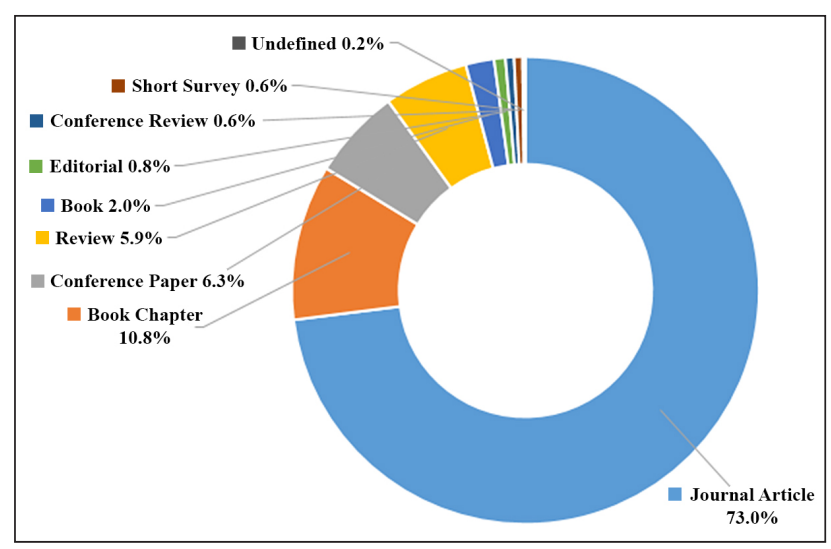

Figure 1. Breakdown of document types included in the Scopus search 


\section{Data mining of the Water Research Commission water governance portfolio}

A database of WRC-funded water governance projects was compiled from a data-mining exercise of the WRC portfolio from the earliest available project meta-data, which was 1990. The data-mining method used was to review all the WRC Knowledge Reviews published electronically. The WRC Knowledge Review is a comprehensive report on projects funded/co-funded by the WRC in a given financial year. The first electronic version dates back to 1990 and provides an excellent overview of the fund portfolios as well as project summaries that include project title, project description, contract value, and duration of project.

A total of 336 projects were identified as water governance projects. The research strategy used to select projects for inclusion in the water governance project list was: (i) classified as such by the WRC under various portfolios (using similar keywords to the bibliometric assessment, i.e., water policy, IWRM, catchment management, water law, water resource management, etc.), or (ii) classified as such by the project team upon review of the project description. The need for additional manual classification by the project team was due to the fact that the WRC only conceptualised its water governance portfolio in the mid-2000s. Before that, the focus of the WRC portfolio was largely on engineering and natural science projects. That is not to say that water governance research was not funded, but it was not mapped to a specific water governance portfolio or key strategic area (KSA). The project team needed to sift through the WRC's earlier (pre-2000) portfolio using keywords used in the bibliometric assessment to identify those water governance projects that may have been classified under, and mapped to, other portfolios, e.g., several projects mapped to the water quality portfolio had significant water governance (water quality management and its regulatory mechanisms) components.

The WRC dataset was cross-checked against the Scopus dataset to compare and contrast trends such as the top publishing institutions and whether they were similar to the top-funded institutions by the WRC, the top publishing authors and whether they reflected a similar WRC project leader cohort, thematic areas most published and themes of WRC projects, etc. Both of these datasets were then also compared to existing global and national literature and similar studies conducted to analyse overall trends and patterns in water governance paradigm shifts over time.

\section{Stakeholder consultations}

In addition to the bibliometric analysis and data mining, the study needed to include a more qualitative, consultative approach on the nature and relevance of the water governance body of research produced in South Africa. This component brought in the users of water governance knowledge, including policy-makers and practitioners, in addition to the generators of this knowledge. The bibliometric analysis and data-mining exercise enabled the project team to map the top publishing authors and institutions of water governance research outputs in South Africa, whereas the stakeholder mapping and engagement exercise focused on answering the second part of the review, namely to analyse the linkages of these institutions and research outputs to government, industry and civil society in order to understand relevant impact of water governance research on users and beneficiaries. The latter involved the identification and mapping of relevant stakeholders in water governance research in South Africa. Stakeholder mapping determines the likely relationship between stakeholders and the project, and helps to identify the appropriate consultation methods for each stakeholder group during the life of the project. Some of the most common methods used to consult stakeholders include: semi-structured interviews, focus group discussions and consultative workshops.
Based on the bibliometric analysis and data-mining exercise conducted, the project team compiled an initial stakeholder database of names, affiliations and contact details, and built on this through the identification of additional stakeholders (for example through a snowball sampling technique) as the project progressed.

A water governance $R \& D$ stakeholder database was produced, and from that a selected and representative group of water governance knowledge generators, policy makers, industry practitioners and 'boundary spanners' (i.e., those individuals who facilitate working across different spheres of government, institutions and sectors) were brought together for a consultative stakeholder knowledge review and agenda-setting workshop in August 2019. The aim of the workshop was to enable the relevant communities of practice to engage with the results of the analysis and begin co-creating a future research agenda for the WRC water governance portfolio, by deliberating on the current state of water governance $R \& D$, and to build on this to map future research focus areas. Group discussions were structured around the following themes:

1. The current key governance challenges and knowledge gaps:
a. What is being done/not done?
b. What research priorities does that suggest?
c. What should we be focusing on now?

2. Future water governance trends:

a. How do you see water governance playing itself out in the medium-long term?

b. To respond to future governance challenges, what should we be doing now? How?

3. A focus on the enabling environment:

a. Is there a water governance $\mathrm{R} \& \mathrm{D}$ community of practice active in the country? Do we need to invest in building a community/strengthening existing communities?

b. What role should the WRC be playing in relation to this community of practice?

c. What resources are needed?

A second consultation was held at the 2019 WRC Biennial Symposium, where the broader research community engaged with the project's findings and the initial inputs of the consultative workshop.

\section{RESULTS}

\section{Bibliometric analysis}

The bibliometric analysis confirmed several dominant narratives that have played out in water governance R\&D in South Africa since the 1990s.

\section{Output}

An upward trend in water governance publications was observed in the period 1990-2019 with a significant spike in 1995 (Fig. 2). The higher number of publications in 1995 is largely due to the $7^{\text {th }}$ International Symposium on River Basin Management, held in the Kruger National Park in 1995 with the theme of River Basin Management for Sustainable Development. This conference resulted in an unusually high number of publications relevant to this study (participatory catchment management), in a special edition of the journal Water Science and Technology dedicated to the symposium proceedings. We compare this study's findings to the global study by Durán-Sánchez et al. (2019) which found an exponential increase in publications from 2009 when, they argue, the real 'boom' of the discipline took place, with about two-thirds of the papers being published between 2013 to 2018, and with 2018 being the year in which the highest number of publications were produced (Durán-Sánchez et al., 2019). 


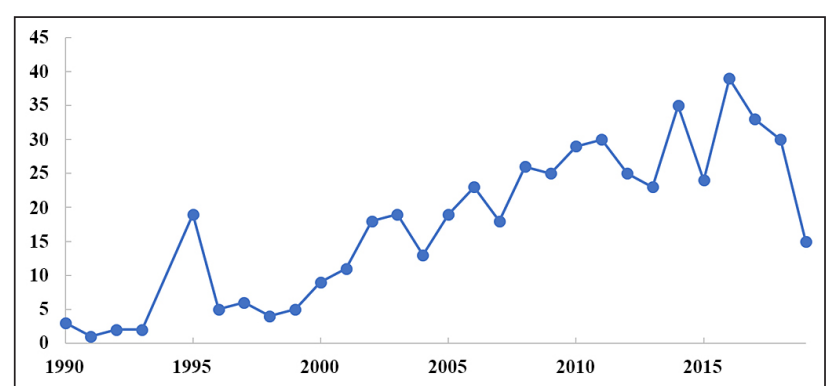

Figure 2. Number of water governance publications per year (1990-2019)

While Durán-Sánchez et al. (2019) note that the first water governance paper appeared in 2003, in the South African dataset used the first related articles date back to 1990, albeit focusing more on a broader water resource management paradigm. It is speculated that this could be due to South Africa's democratization process and the attention placed on IWRM (even if not referred to by that name yet) and participatory forms of management in the lead up to the historic 1994 election and the constitutional settlements of 1993. Specifically, since 2013, roughly $40 \%$ of the total of Scopus articles have been published. This does not corroborate the findings of Durán-Sánchez et al. (2019), who found a 70\% concentration of articles between 2014 and 2019, and who related this to the fact that the 'water governance' concept did not begin to be considered as an independent discipline until the definition by the UNDP Water Governance Facility at SIWI (WGF).

\section{Profile of top publishers}

Figure 3 illustrates the top 50 institutions publishing water governance research in Scopus, in terms of the number of contributing authorships linked to institutions - local and international. The Council for Scientific and Industrial Research (CSIR) is at the top of the list ( 83 publications), followed by the University of KwaZuluNatal (UKZN) with 64 publications, the Department of Water and Sanitation (DWS) (then Department of Water Affairs and Forestry) with 34 publications, and the International Water Management Institute (IWMI) with 31 publications. Figure 3 further illustrates the relative contribution of local versus international institutions. While 9 of the top 10 institutions are South African, several international institutions such as IWMI, the Norwegian University of Life Sciences (Universitetet for Miljø- og biovitenskap) (with 15 publications), the Institute of Development Studies (IDS) (with 14 publications), the University of Sussex (with 12 publications), and Wageningen University (with 11 publications) also play a key role as publishers of water governance research on South Africa. Another significant issue worth noting is that there is generally an under-recognition of the role of DWS as both a generator and user of knowledge. Due to acclaimed research generated from the DWAF-affiliated Institute for Water Quality Studies and other knowledge hubs within the Department, DWS is the third biggest publisher of water governance $\mathrm{R} \& \mathrm{D}$ in the dataset. This is a significant finding and demonstrates the strong contribution to water governance knowledge by a government department. Of concern, however, is the downward trend in the production of knowledge by the department over time.

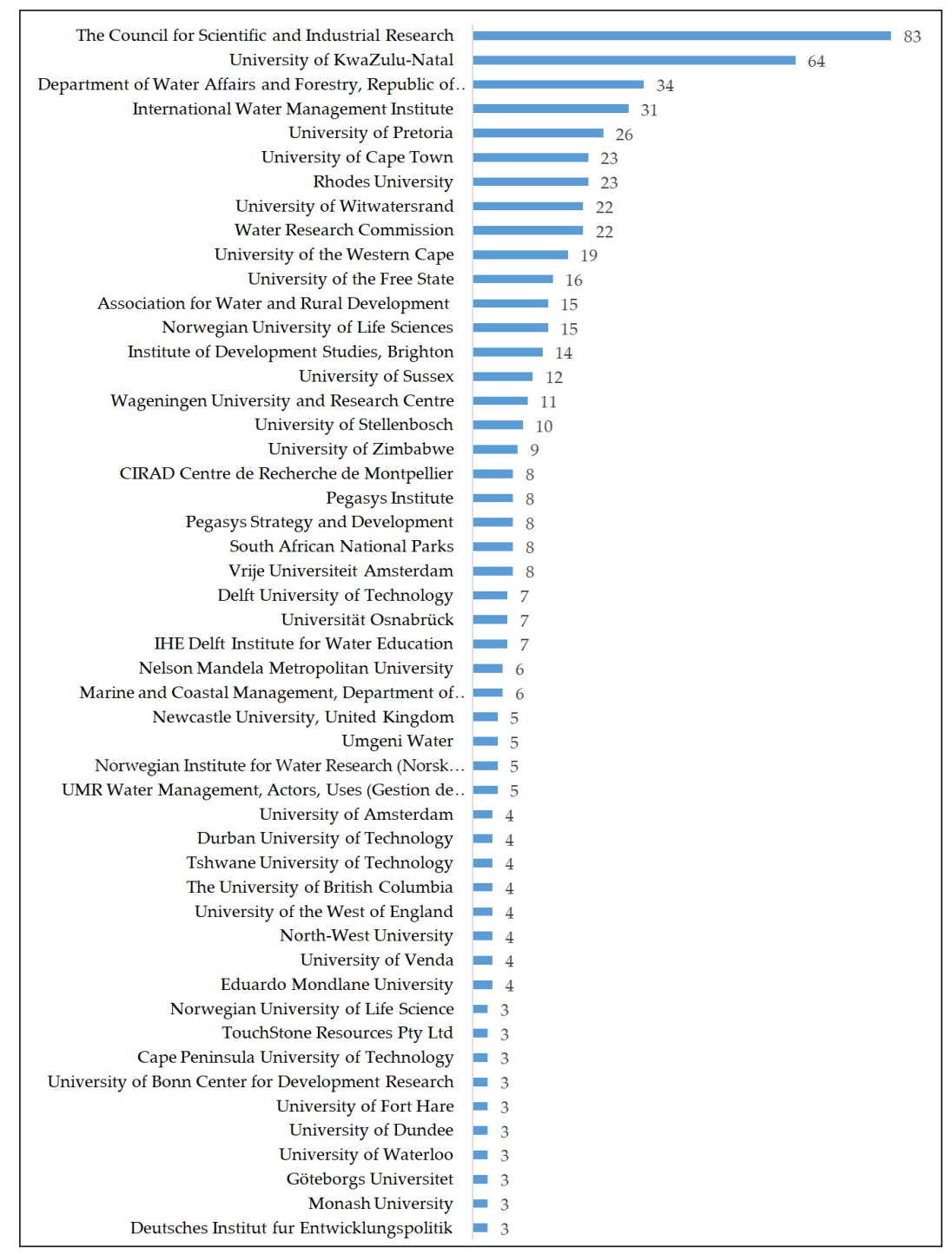

Figure 3. Top 50 institutions producing water governance R\&D on South Africa 
The top publishing authors came from a wide range of disciplines, including social science (political science, economics, international relations, sociology, gender studies), and natural science (environmental management, hydrology, climate change, etc.) Dr Barbara van Koppen (IWMI) is listed as the top publishing author followed by Dr Anthony Turton (Water Chamber), Ms Barbara Schreiner (Water Integrity Network), Dr Richard Meissner (CSIR) and Dr Sharon Pollard (AWARD) (Fig. 4). It is interesting to note that many of the top individual publishers (Ashton, Schulze, Jewitt, Van Wilgen, Hughes, Le Maitre, etc.) are top publishing authors in other technical domains, e.g., hydrology, climate change modelling, aquatic ecology, etc., who later in their careers start to write about the impact of governance challenges on their respective technical domains.

\section{Publication reach: Potential influence}

The 511 articles in Scopus received a total of 5863 citations, which averaged 14.97 citations/document over the period between 1990 and 2019. A more detailed citation analysis revealed that $1.2 \%$ of publications (6 publications in total) received more than 100 citations; $3.5 \%$ (or 18 publications) from $50-100$ citations; and $26.8 \%$ from $10-49$ citations. Additionally, $23.29 \%$ of articles did not receive any citation. The two articles with the highest citation average per year were: (i) 'Institutional design propositions for the governance of adaptation to climate change in the water sector' and (ii) 'The working for water programme: Evolution of a payments for ecosystem services mechanism that addresses both poverty and ecosystem service delivery in South Africa' both with 19 citations per year on average (up to 2019) (Table 1).

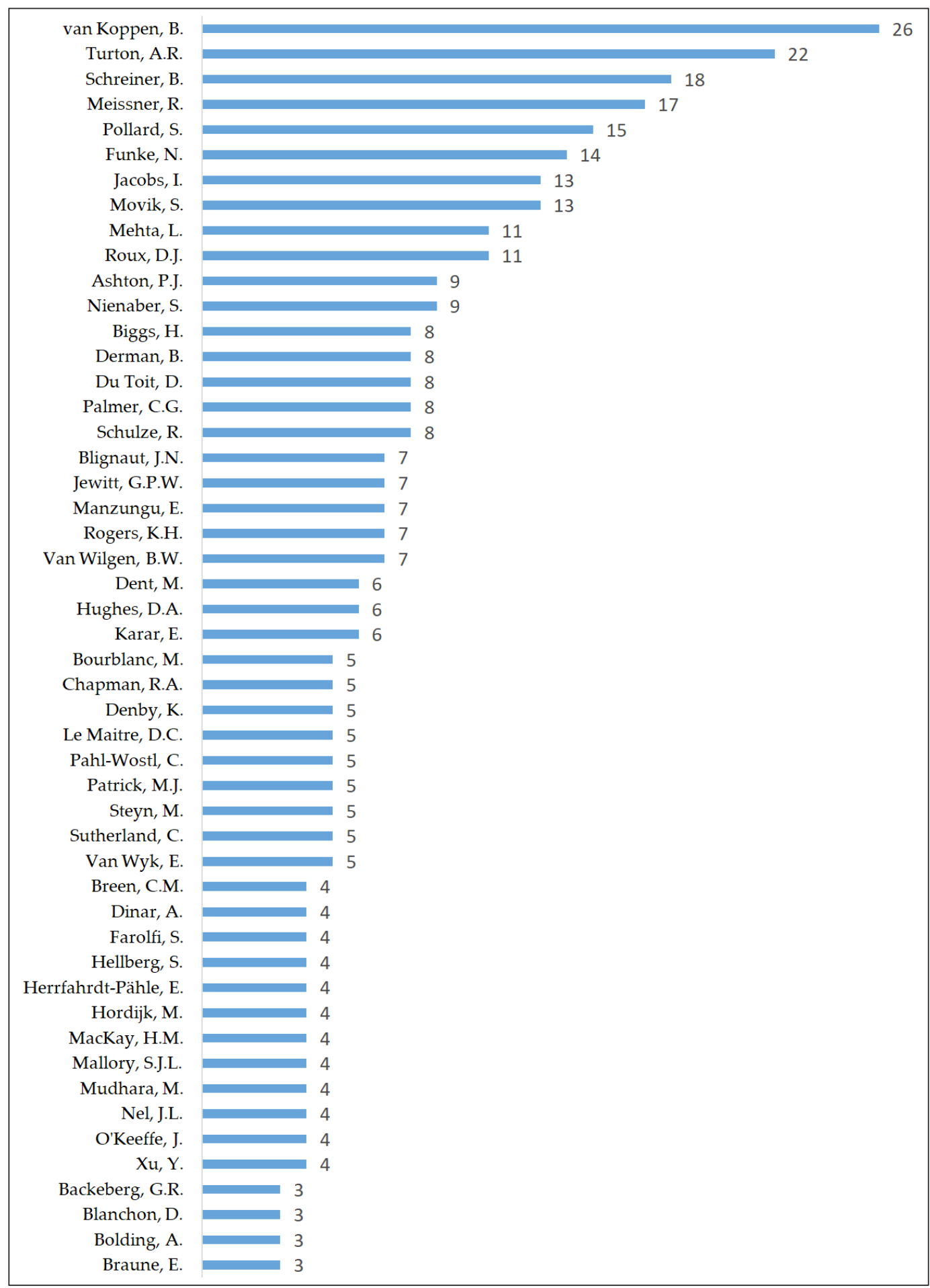

Figure 4. Top 50 authors on water governance in South Africa 
Table 1. Most influential articles according to the number of citations

\begin{tabular}{|c|c|c|c|c|c|}
\hline Authors & Title & Year & Source title & Cited by & $\begin{array}{c}\text { Average citations per } \\
\text { year (up to 2019) }\end{array}$ \\
\hline $\begin{array}{l}\text { Huntjens P, Lebel L, } \\
\text { Pahl-Wostl C, Camkin J, } \\
\text { Schulze R, Kranz N }\end{array}$ & $\begin{array}{l}\text { Institutional design propositions for the } \\
\text { governance of adaptation to climate } \\
\text { change in the water sector }\end{array}$ & 2012 & $\begin{array}{c}\text { Global Environmental } \\
\text { Change }\end{array}$ & 135 & 19 \\
\hline $\begin{array}{l}\text { Turpie JK, Marais C, } \\
\text { Blignaut JN }\end{array}$ & $\begin{array}{l}\text { The working for water programme: } \\
\text { Evolution of a payments for ecosystem } \\
\text { services mechanism that addresses both } \\
\text { poverty and ecosystem service delivery } \\
\text { in South Africa }\end{array}$ & 2008 & Ecological Economics & 207 & 19 \\
\hline Ragab R, Prudhomme C & $\begin{array}{l}\text { Climate change and water resources } \\
\text { management in arid and semi-arid } \\
\text { regions: Prospective and challenges for } \\
\text { the 21st century }\end{array}$ & 2002 & $\begin{array}{l}\text { Biosystems } \\
\text { Engineering }\end{array}$ & 241 & 14 \\
\hline $\begin{array}{l}\text { Le Maitre DC, Van Wilgen } \\
\text { BW, Gelderblom CM, } \\
\text { Bailey C, Chapman RA, } \\
\text { Nel JA }\end{array}$ & $\begin{array}{l}\text { Invasive alien trees and water resources } \\
\text { in South Africa: Case studies of the costs } \\
\text { and benefits of management }\end{array}$ & 2002 & $\begin{array}{l}\text { Forest Ecology and } \\
\text { Management }\end{array}$ & 176 & 10 \\
\hline Warner JF & $\begin{array}{l}\text { More sustainable participation? Multi- } \\
\text { Stakeholder Platforms for integrated } \\
\text { catchment management }\end{array}$ & 2006 & $\begin{array}{l}\text { International Journal } \\
\text { of Water Resources } \\
\text { Development }\end{array}$ & 117 & 9 \\
\hline $\begin{array}{l}\text { Le Maitre DC, Van Wilgen } \\
\text { BW, Chapman RA, Mckelly } \\
\text { DH }\end{array}$ & $\begin{array}{l}\text { Invasive plants and water resources in } \\
\text { the Western Cape Province, South Africa: } \\
\text { Modelling the consequences of a lack of } \\
\text { management }\end{array}$ & 1996 & $\begin{array}{c}\text { Journal of Applied } \\
\text { Ecology }\end{array}$ & 181 & 8 \\
\hline
\end{tabular}

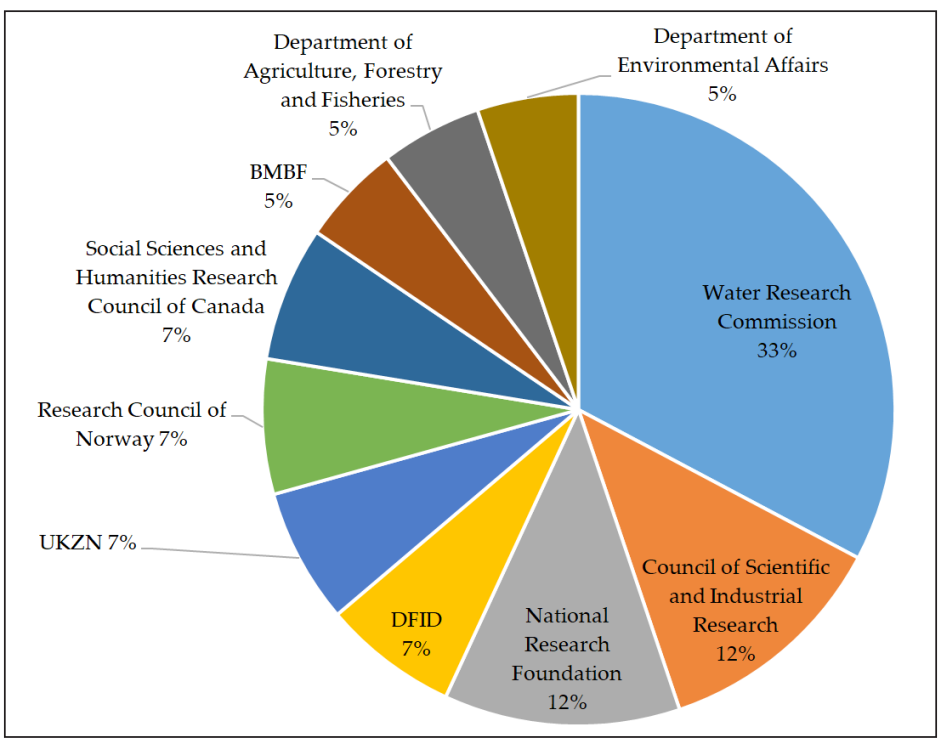

Figure 5. Top 10 funders of water governance R\&D in South Africa

Publications focusing on the governance of climate change and ecosystem services received a greater number of citations in the dataset.

\section{Focus and funding}

Figure 5 shows the top 10 funders of water governance research in South Africa. The WRC is the largest funder of this portfolio at $33 \%$, followed by the NRF and the CSIR at $12 \%$ each, and DFID, UKZN, the Research Council of Norway, and the Social Sciences and Humanities Research Council of Canada all contributing 7\% each to water governance research funding.

\section{Paradigmatic trends}

As previously noted, the bibliometric analysis conducted in this study confirmed previously documented trends, but sought to focus on even more recent developments up to 2019 (Fig. 6).
Indeed, as Siebrits et al. (2014) observe, this study also observed the 1990s trend that saw the emergence of participatory management and its metamorphosis into 'integrated catchment management' (ICM) with a strong focus on water quality management. Indeed, the South African water governance R\&D dataset confirms an earlier focus on water governance than similar global datasets, arguably because of South Africa's democratization process and the attention placed on participatory forms of management (e.g., participatory catchment management).

A decade later, the focus expanded to water as a human right and broader equity issues. We also see the emergence of overarching normative conceptualisations and inclusive and participatory approaches such as IWRM and sustainable development. Ten years into the new democratic dispensation with the new policy directions well-articulated, we see a clustering of analyses on water policy reform and its impact on broader water resource management. 


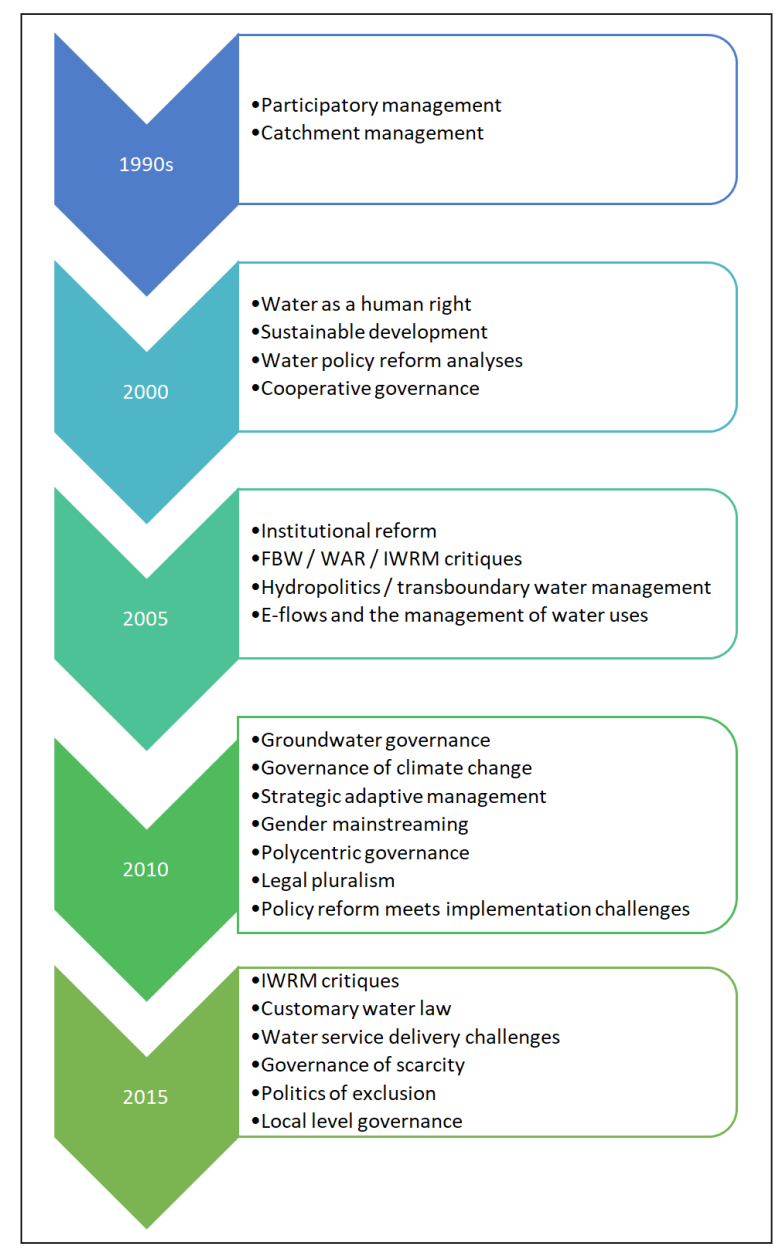

Figure 6. Dominant narratives in water governance R\&D in South Africa since the 1990s

Towards the middle of the 2000s, the first critiques of these policy reforms - free basic water (FBW); water allocation reform (WAR); IWRM - start to emerge. We also see the narrative of water scarcity and its impact on governance as well as the intersectionality between technical domains of environmental flows and governance, particularly the management of water uses. This was also the heyday of hydro-politics and transboundary water governance, given the ratification of the Southern African Development Community's Revised Protocol on Shared Watercourses, the establishment of transboundary river basin organisations and the development of several river basin agreements, and with several seminal research products and schools of thought (the CSIR Water Governance Group) documenting and analysing South Africa's role in regional water politics.

The start of the 2010s introduced a new wave of domain-specific governance research. As such, a focus on groundwater governance, the politics of climate change and, later still, the water-energyfood (WEF) nexus and its related governance challenges, started to receive greater attention. In addition, cross-cutting focus areas such as gender mainstreaming and governance, and strategic adaptive governance also re-emerged. In the period from 2010 2015, we also see several studies adopting theoretical frameworks based on legal pluralism and polycentric governance to unpack the interplay between water governance at different levels of scale, and the resurgence of water rights and how they are implemented at the local community level. Much of the water governance research published during this time includes the underlying sentiment, 'Our water policies are good, the problem lies in their implementation.'

From the latter half of the 2010s up to the present day, we see a shift in focus (although not yet mainstream) acknowledging that some aspects of our water policy reform, e.g., the permits system, may not have been as transformative as we would have liked them to be by now. While it may be a bridge too far to claim that there is an emergence of a paradigmatic shift from 'South African water policy is good just not well implemented' to 'There are some critical flaws to South African water policy that need to be addressed,' there is certainly a school of thought that has gained a foothold looking at the decolonisation of water law (Van Koppen and Schreiner, 2018).

Research-based policy dialogue in Africa during the past decade has identified major challenges with the permit systems that currently prevail in four out of five Sub-Saharan African countries, and generated interest among water authorities, water lawyers and researchers in alternatives, in particular 'hybrid water law' The main challenge identified was the logistic inability of underresourced water authorities to implement the statutory blanket permit systems among millions of smallholders. Authorities simply cannot create awareness and process applications, let alone enforce the conditions of permits among these masses of scattered and remote small-scale water users. However, without a permit, investments in water infrastructure for small-scale productive uses are formally illegal. De minimis productive water uses that are exempted from the obligation to apply for a permit have a weaker legal standing, if not by law then in its implementation

This legislative criminalization and marginalization contradicts national goals of agriculture-led economic growth, food security, nutrition, and poverty alleviation. It also counters governments' growing understanding of, and support to, farmer-led irrigation development. Realizing the colonial roots of permit systems and their post-colonial promotion as ingredients of the IWRM discourses initiated by the North since the 1990s, hybrid water law has emerged a promising alternative (Van Koppen and Schreiner, 2018). 
In a similar vein, the challenges of water service delivery and the politics of exclusion have also stimulated a reactionary, perhaps even revolutionary, focus on bottom-up/community-driven self-supply initiatives, as well as an increasing acknowledgement of the role that customary water law plays in water governance at the community/ local level. Finally, we see a greater focus in the present-day water governance literature on water integrity, good corporate governance, risk management, compliance and, indeed, calling attention to the mismanagement of the sector from a normative perspective, although only a few alternative models are currently proposed.

\section{Data mining of the WRC water governance portfolio}

\section{Trends in awarding of WRC water governance research projects}

A total of 336 projects were identified as water governance projects between 1990 and 2019, either classified as such by the WRC under various portfolios, or by the project team upon review of the project description in the Knowledge Reviews. Of these, 333 projects were awarded to South African institutions, while only 3 were awarded to international institutions (European Science and Environment Forum, IUCN, and the Institute for Security Studies).

The majority of projects were awarded to the private sector (consultants) at 43\%, higher education institutions (HEIs) at $33 \%$, and significantly fewer to parastatals and government agencies at $12 \%$ (Table 2). The remainder is spread across national government departments, networks and associations, NGOs, non-profit organisations (NPOs) and other institutions. However, the institution that received the greatest number of research project contracts from 1990-2019 on water governance was the CSIR (with 28 projects funded), followed by UKZN at 22 projects; and the Palmer Development Group at 17 projects (Fig. 7). This is consistent with the bibliometric assessment confirming the CSIR and UKZN as the top two publishing institutions on water governance in the country.
In total, the WRC awarded over 300 million ZAR to water governance and related research from 1990 to 2019. As indicated in Table 2, the bulk of this funding was awarded to HEIs at nearly 150 million ZAR followed by the private sector at just over 100 million ZAR and parastatals/government agencies at over 40 million ZAR (Table 2). It is noteworthy to mention that while HEIs received a lower number of projects, the individual grant amount awarded per project was generally greater, suggestive of HEI projects being of longer duration (reflective of long-term research and post-graduate study support) than those undertaken by consultants.

The allocation of WRC funds to water governance $R \& D$ is, at the least, $15 \%$ of the total WRC portfolio (classified by the WRC in their Knowledge Reviews as 5\% water policy; 10\% IWRM) but may be more if we were to take into consideration several studies mapped to other KSAs that have indirectly covered issues pertaining to governance. The WRC funding portfolio is reflective of the bibliometric analysis in terms of the key institutions publishing water governance R\&D (CSIR, UKZN, UCT, Rhodes University), although interesting outliers such as the Palmer Development Group, who received a high number of WRC-funded projects in the early 1990s, have not resulted in the expected number of research publications. This can however be expected given that the focus of private consultancies such as this is not necessarily to contribute to the knowledge base in the form of research publications but to address a specific client need, documented in reports and other grey literature. Finally, the trend analysis confirms a responsive/reactive analytical trend vs a proactive/forecasting/predictive trend. Acknowledging the publication lag, i.e., that publications tend to be published 1, 2 or several years after research has been concluded, research outputs were responsive (at the best of times) or reactive (at the worst of times) to earlier trends and developments in the water governance landscape, and not necessarily addressing the governance challenges faced by the water sector at the time of publication.

Table 2. Distribution of WRC-funded water governance R\&D projects and funding allocation according to institution type (1990-2019)

\begin{tabular}{lccc}
\hline Institution & Projects awarded (\%) & Funding allocation (ZAR) & Average funding per project (ZAR) \\
\hline Government department (national) & 1 & 200400 & 100200 \\
Higher education institution (HEI) & 33 & 149633566 & 1348050 \\
Network / association & 1 & 1730000 & 432500 \\
NGO / CBO & 3 & 7628660 & 635722 \\
NPO & 4 & 9840000 & 820000 \\
Other & 2 & 5112000 & 852000 \\
Parastatal / government agency & 12 & 44197405 & 1052326 \\
Private sector (consultant) & 43 & 101603219 & 705578 \\
Unknown & 1 & 800000 & 266667 \\
\hline
\end{tabular}

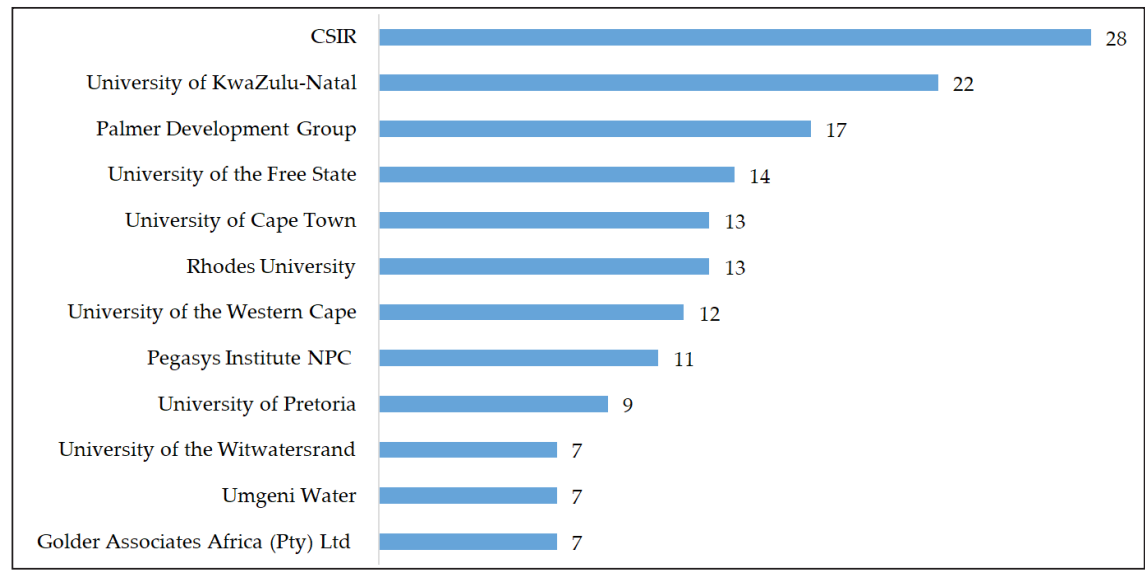

Figure 7. Top 10 institutions awarded water governance research project contracts by the WRC (1990-2019) 


\section{Stakeholder consultation}

Stakeholder consultations were structured around the following themes as derived from the bibliometric analysis and datamining exercise: the current key governance challenges and knowledge gaps; future water governance trends; and the enabling environment. Four main areas emerged as defining the current state of water governance research knowledge and its uptake: (i) research relevance and responsiveness; (ii) availability and nature/source of funding; (iii) addressing the implementation challenge, and (iv) the silo approach. In terms of stakeholders perceptions of future water governance trends and needs, three issues were highlighted: (i) the focus on institutional integrity and good corporate governance; (ii) the need for a rapid response water governance research mechanism; and (iii) transformation of and within the water governance R\&D community. Finally, discussions on the enabling environment highlighted two key elements: (i) packaging and communication of water governance research, and (ii) the role of the WRC.

\section{Stakeholder perceptions on current water governance challenges and knowledge gaps}

\section{Research relevance and responsiveness}

Stakeholders observed that current national water governance R\&D outputs are largely 'passion-driven' as opposed to 'needs-based', in that researchers tend to research what they enjoy/are passionate about instead of addressing an important national governance challenge. This is clearly not a uniquely South African affliction, as attested by the general observation by Green (2007), in relation to governance research for a project spanning four continents, of scientists' selfconceptualisations as gift bearers doing curiosity-driven research that is then turned into practical application by someone else. On the other hand, stakeholders also acknowledged the individualisation of research focus, and the world views shaping researchers' approaches to water governance and how they research it.

In addition, stakeholders agreed with the bibliometric analysis that confirmed a reactive/responsive analytical trend vs a proactive/ forecasting/predictive trend. It emerged from the discussion that research outputs fall behind current water governance issues, particularly in a fast-paced environment where there is the need for research knowledge to respond with agility to emerging issues. Increased support from the research fraternity to government departments is needed particularly in crisis periods where decisions have to be made at a political level. On the other hand, this could also reflect the difference between basic/fundamental research and strategic (needs-driven) research. Articles published in peerreviewed journals tend to reflect the research interests of academics which are developed over time and may not reflect an immediate identification of need. A scan of the WRC project titles in the water governance data-mining dataset reflects a more nuanced picture of research that responds to water sector governance challenges over time.

\section{Availability and nature/source of funding}

There is a need for mindfulness in how funding flows influence what is researched, particularly how international interests shape the local water governance agenda. Funding availability was discussed in two instances: (i) where resources available for research are increasingly under strain, thus limiting the scope of areas that can be addressed; (ii) when research agendas are guided by the source of funding rather than the need, typically related to international donor agendas. Resources and interests external to Africa have been shown to exert a strong influence on the research priorities of countries in Africa (Pouris, 2017). This oftentimes stands in the way of research innovation and the relevance of research for local users. It also results in the implementation of isolated projects. In this regard also, stakeholders in the consultative sessions criticized the water governance R\&D community for not being good at building a pipeline of expertise and a programmatic approach to address key challenges.

Indeed this also raises the controversial issue of the politics of R\&D funding and funding flows: to which institutions and why; the magnitude of funding allocations to specific institutions and research domains; the expansion of research funding beyond basic and applied research into development; how much of R\&D budgets are dedicated to commissioned/directed research vis-àvis open/self-initiated research, and the latter determining the proportion of funding dedicated to addressing client-specific challenges vs unrestricted research that allows for greater innovation from within research communities.

\section{Addressing the implementation challenge}

There is a need to interrogate policy implementation/lack thereof as a research field including the need for embedded research. Stakeholders raised several issues pertaining to policy implementation challenges. The first was the well-acknowledged inadequacies of government to implement policy due to, amongst other things, limited appropriate planning, capacity challenges, mismanagement and corruption, as well as the lack of clearly articulated impact pathways and/or theories of change. This is compounded by weak support from the research community (in terms of implementation) for government departments, who at times do not have the required technical capacity to appropriately execute policy recommendations.

Further, impact assessments of existing policies have not been adequately conducted. Not only is there a need for a greater partnership between government and the research community to co-create and jointly implement evidence-based governance solutions, but there is also a need for 'embedded research' and the need to study implementation as a research field - to-date, an untapped value-add of the social science enterprise and its potential contribution to water governance R\&D. Embedded research has been defined as the collaborative approach between academia and other host organisations in the public or private sectors, where individuals or teams are based at, or affiliated with, host organizations with the aim of implementing collaborative research agendas (McGinity and Salokangas, 2014). The relationship between the researcher and the host institution is mutually beneficial in that the researcher is provided with greater access to the host institution (in the form of data collection and/or research funding), and the host institution benefits from better access to academic knowledge, networks and critical approaches to developing organisational policies and practices (McGinity and Salokangas, 2014). Joint research projects, sabbaticals, associate professorships, and postgraduate study programmes for policy-makers are some of the ways in which embedded research can be undertaken.

\section{The silo approach}

There is a need to explore the impact of 'boundary spanners' and to profile these champions. Stakeholders from both government and the research community lamented that interdepartmental relationships within government are not solution-oriented, in that departments frequently still operate in silos with few cases of effective coordination and alignment between them. As a result of this silo approach, there is no learning culture and no evaluation of policy implementation failures or, similarly, no evaluation of successes. Stakeholders suggested that we need to look at the impact of 'boundary spanners' - those individuals that can and do work across institutions, spheres of government, sectors and disciplines, profile them as champions and identify the external factors that enable or inhibit their boundary-spanning activities. 


\section{Stakeholder perceptions on future water governance trends and needs}

\section{Focus on institutional integrity and good corporate governance}

Echoing the broader governance debates currently underway in South Africa, there will be an increasing emphasis placed on compliance, dealing with corruption as well as institutional integrity and corporate hygiene. The water sector, including the research community, needs to address the elephants in the room' (corruption vs water integrity, dysfunctional government departments, etc.).

\section{The need for a rapid-response water governance research mechanism}

Several stakeholders in the water R\&D community have, for a few years, been advocating for the development of a new trend in water governance research - a constructive, adaptive and rapidresponse research mechanism in an environment of increasing change and uncertainty. The need for solution-oriented water governance $\mathrm{R} \& \mathrm{D}$, including rapid-response assessments, would serve as a support mechanism to government in responding to immediate crises and challenges in the short-term.

\section{Transformation of and within the water governance R\&D community}

From the bibliometric analysis and findings of the data-mining exercise, and specifically the analysis of top-publishing individuals leading water governance $\mathrm{R} \& \mathrm{D}$, stakeholders noted the wide range of disciplinary backgrounds represented, from natural and environmental sciences to political science and economics. However, despite the disciplinary diversity, the demographic profile of the leading water governance researchers still reflects a largely white, male cohort (refer to Fig. 4).

In addition to its lack of diversity, the size of the community was also raised as an issue. Stakeholders put forward, based on their intuition rather than any quantitative analysis, that the South African water governance epistemic community remains small. From a total of 144 authors catalogued by the bibliometric dataset, the top 20 authors account for 239 (47\%) of the total 511 publications. This can be seen as a high concentration of water governance research being conducted by a small minority (14\%) of the author cohort. This is not unusual, however, and reflects a nearly universal trend across all fields, captured in Lotka's Law of Productivity (Lotka, 1926). Further research is needed to quantify the size of the water governance R\&D community in South Africa.

Therefore, while the size of the epistemic community cannot necessarily be considered small, there are a few individuals publishing the majority of water governance research. There is therefore a need to focus on the transformation of the water governance $\mathrm{R} \& \mathrm{D}$ community that promotes the inclusion of more, and particularly, younger, black and female voices. Indeed, the knowledge being generated, research agendas being pursued, etc., are reflections of dominant paradigms and values held by the dominant voices in this R\&D community. Promoting the plurality of voices, perspectives and priorities ensures that transformation in this context is not just about increasing the diversity of researchers from a demographic point of view, but equally about challenging the hegemony of paradigms.

\section{The enabling environment}

Stakeholders expressed the view that research evidence should be packaged to suit different target groups and/or contexts to enhance uptake. Academic publications may not reach the targeted stakeholders who are in the position to effect change or who may benefit from research outputs. Specific sentiments expressed by government representatives during both the workshop and the WRC Symposium session could be summarised as follows:

- Don't complicate it - sharpen the message by keeping it clear and easily understandable for policy-makers.

- Understand your audience - researchers often have little understanding/appreciation of the time constraints government officials are under, or of the nature of their procedures. A greater understanding of this on the part of researchers can go a long way in helping them package information in appropriate user-friendly formats that help address a specific need by government.

- Government needs to engage with more voices from the research community, especially in times of crisis - government officials expressed the need for greater engagement with evidence-based research from a greater number of researchers to allow for more perspectives and voices to be heard and shared.

- The research community would be more impactful if they were better coordinated - government officials articulated the unfortunate example when the impact of the research community is diluted because it is uncoordinated in its engagement with government, thus presenting confusing and conflicting messages.

\section{The role of the WRC}

Key thoughts put forward with regards to the role of the WRC in driving water governance knowledge generation include:

- Fragmented project outputs do not provide a consolidated picture of the problems addressed. The WRC should work towards a dedicated water governance R\&D portfolio, and position it as the primary coordination mechanism for water governance evidence-based advisory services for government.

- The pool of researchers was seen as limited and homogenous in its profile, and could negatively impact knowledge generated. The WRC should focus its attention on promoting young, black and female researchers to work in this field by promoting capacity building through student support and project leadership.

- A narrow scope of research was identified as a current limitation, with the bulk of documented research on institutional arrangements such as catchment management agencies and IWRM. More focus still needs to be placed on the intersectionality between land and water rights, behavioural studies on water consumption and demand management, particularly in times of growing scarcity, alternative institutional models in decentralised systems, and the political economy of water and aspects of equity.

\section{DISCUSSION}

Based on the study's findings, we present arguments for future needs in water governance knowledge generation in which the WRC can play a significant role.

Several key focal areas in which to concentrate future water governance $\mathrm{R} \& \mathrm{D}$ attention emerged from conversations with generators and users of water governance knowledge in South Africa. Given the notable gap between policy aspirations and current realities, it is unsurprising that an emerging critical future area of focus is research on implementation in order to better understand the policy-implementation gap and current policy landscape. This includes paying greater attention to the political 
economy of water, and identifying factors that may enable or inhibit the application of new knowledge. Equity and redress continue to be research priorities, primarily in relation to the particular legacy of race-based dispossession of land and water resources, considering the lack of substantial progress made to date in implementing legislation designed to address this legacy. Echoing the broader governance debates currently underway in South Africa there will be an increasing emphasis placed on integrity in the water sector, dealing with corruption as well as institutional integrity and corporate hygiene. Other future directions include research on adaptive governance in the face of uncertainty and change; intergovernmental relations for water resource management and water service provision; customary and informal approaches to water management; economic regulation; and the theory and practice of decentralisation in relation to water.

The shift in emphasis to direct research attention to policy implementation accords with the encouragement by Kjellen et al. (2015 p. 4) to understand governance as, 'a dynamic and process related concept: working with the process can be just as important as the water reform content itself.' The focal areas identified for future research effort in South Africa show similarities with the framing by Araral and Wang (2013) of a 'water governance 2.0' research agenda rooted in theoretical tools drawn from public sector economics, institutional economics, political economy and public administration. The interest of public economics in equity as well as efficiency, and the role this creates for the state, are points of convergence between the two agendas. The surfacing of the interaction between the politics and economics of water, as a lens for understanding various seemingly intractable challenges for water governance, also comes through clearly in both. While human rights-based approaches may be implicit in elements of the water governance 2.0 research agenda, they feature far more prominently in the South African agenda.

Several stakeholders in the water R\&D community have, for a few years, been advocating for the development of a new trend in water governance research - a constructive, adaptive and rapid-response research mechanism in an environment of increasing change and uncertainty. The need for solution-oriented water governance R\&D including rapid-response assessments would serve as a support mechanism to government in responding to immediate crises and challenges in the short-term. A potential model for such a mechanism exists within a South African context, in the form of an agreement in place between the Department of Environmental Affairs, Forestry and Fisheries (DEFF) and the Council for Scientific and Industrial Research (CSIR). This arrangement enables DEFF to submit urgent research questions (along with the necessary funding) for response by the CSIR within 30 days. The questions typically stem from the implementation by DEFF of its mandate, with responses taking the form of concise research reports. With some adjustment to fit the funding and institutional arrangements within the water sector, this model could provide a further modality for the research community to be responsive to emerging, urgent questions from policymakers.

Stakeholders expressed the view that knowledge generated should be packaged to suit different target groups and/or contexts to enhance uptake. Academic publications may not reach the targeted stakeholders who are in the position to effect change or who may benefit from research outputs. This highlights that, in terms of ensuring relevance and accelerating the translation of research outcomes into policy and practice, the way in which the water governance R\&D community of practice operates may be as important as its choice of research focal areas.

Several potential modalities were put forward in discussions involving those generating water governance knowledge and those using it. One involves deliberately designing approaches for planning, doing and reviewing research that more closely and consistently include the eventual users in the knowledge generation process. Another potential modality comes in the form of embedded researchers employed by universities or other research organisations, but housed within another organisation for the purpose of implementing a joint research agenda (Cheetham et al., 2018). They are understood here to be researchers. Both these modalities - closer involvement of knowledge users in knowledge generation and embedded researchers - help to remove the disconnect between the places where knowledge is generated and where it will be applied.

\section{CONCLUSION}

In addition to recommendations for the broader water governance R\&D community and discourse, the study presents several recommendations as they pertain to the WRC. The WRC has an important role to play in driving the water governance research agenda, in light of the new combined ministry of Human Settlements, Water and Sanitation. A consideration of the following was put forward for the WRC:

- Convening an active community of practice. The WRC should lead the establishment of a national community of practice for water governance experts that can respond to issues with agility, bringing together and strengthening the smaller governance schools of thought/communities currently operating at universities and other research institutions. This can be done by hosting national dialogues and stakeholder workshops, as well as through dedicated water governance research calls that specifically require partnerships across institutions. An important role for such a community of practice is to draw in all relevant disciplines that should be active in water governance $R \& D$ and encourage greater interdisciplinary and transdisciplinary collaboration. There is an inherent need for such approaches in water governance, but these have not been well represented in the literature (Araral and Wang, 2013). While some promising examples exist in the South African context (e.g., Weaver et al., 2017; Wolff et al., 2019), further encouragement is required.

- Effective knowledge dissemination. The WRC should furthermore consolidate and package knowledge generated from different projects to provide an overall picture for the problems being addressed in user-friendly formats that appeal to government officials. In the same vein, the WRC would need to look into developing an advisory service platform to rapidly deploy evidence-based advice to government and other partners.

At a broader level, the multidimensional nature of water governance, stemming from the multiple uses and sources of water, puts water governance at the centre of the global water crisis discourse. South Africa is not exempt from global pressures such as climate change, urbanisation and population increase, to which water is invariably linked, in addition to its own local context. Responding to these challenges requires effective governance systems and structures. An increase in the number of voices demanding a seat at the table along with the increasing complexity of socio-political and environmental challenges, calls for a proactive approach to knowledge generation.

Learning from the past to inform the future is necessary and more so when done systematically to address targeted issues. This report showed that past knowledge generated for water governance in South Africa responded reactively to the issues of the time, but oftentimes tended to be based on researchers' individual interests and passions as opposed to being needsbased in responding to the key governance challenges at the time. 
Going forward, however, research knowledge will have to assume a certain agility that can keep up with the demands for timely evidence-based responses. As such, a more practical approach to research has to be considered which actively seeks to implement research knowledge.

The WRC is strategically positioned to direct and coordinate the future of water governance research by convening a national community of practice that is well-coordinated in its engagement with government. While this short-term project kick-started an important process toward setting the agenda for future investment in water governance research for South Africa, it is now imperative to not only build a programmatic approach and pipeline of diverse expertise, but also invest in strengthening the enabling environment through the strengthening of the water governance R\&D community of practice, as well as a dedicated rapid-response mechanism to adequately support government in responding to immediate challenges.

\section{ACKNOWLEDGMENTS}

This research was made possible by a WRC-funded project (Project number: K5/2911/1\&2). For more details, refer to the Final Report, WRC Report No. 2911/1/20 (Jacobs-Mata and Mukuyu, 2020). Appreciation is extended to field experts and officials from the Department of Water and Sanitation, South Africa, for their insights and contribution to this paper as part of the stakeholder engagement and consultation process.

\section{REFERENCES}

AHLERS R and ZWARTEVEEN M (2009) The water question in feminism: water control and gender inequities in a neo-liberal era. Gend. Place Cult. 16 (4) 409-426. https://doi.org/10.1080/ 09663690903003926

ALLAN JA (2001) The Middle East Water Question: Hydropolitics and the Global Economy. I.B Tauris, London and New York. 400 pp.

ALLAN JA (2005) Water in the environment/socio-economic development discourse: sustainability, changing management paradigms and policy responses in a global sytem. Gov. Oppos. $\mathbf{4 0}$ (2) 181-199. https://doi.org/10.1111/j.1477-7053.2005.00149.x

ARARAL E and WANG Y (2013) Water Governance 2.0: A review and second generation research agenda. Water Resour. Manage. 27 (11) 3945-3957. https://doi.org/10.1007/s11269-013-0389-x

BAKKER K (2008) The "commons" versus the "commodity" alterglobalization, anti-privatization and the human right to water in the Global South. In: Mansfield B (ed.) Privatization: Property and the Remaking of Nature-Society Relations. Blackwell Publishing, Oxford. https://doi.org/10.1002/9781444306750.ch2

BATCHELOR C (2006) Water governance literature assessment. Report contributing to the scoping exercise managed by IIED to help develop a DFID research programme on water ecosystems and poverty reduction under climate change. https://pubs.iied.org/ G02523/

BOELENS R and ZWARTEVEEN M (2005) Prices and politics in Andean water reforms. Dev. Change. 36 (4) 735-758. https://doi. org/10.1111/j.0012-155x.2005.00432.x

CHEETHAM M, WISEMAN A, KHAZAELI B, GIBSON E, GRAY P, VAN DER GRAAF P and RUSHMER R (2018) Embedded research: a promising way to create evidence-informed impact in public health? J. Public Health (Oxf.) 40 (1) i64-i70. https://doi.org/10.1093/ pubmed/fdx125

COLEBATCH HK (2014) Making sense of governance. Polic. Soc. 33 (4) 307-316. https://doi.org/10.1016/j.polsoc.2014.10.001

DURAN-SANCHEZ A, DE LA CRUZ DEL RÍO-RAMA M, ÁLVAREZGARCÍA J and CASTELLANO-ÁLVAREZ F (2019) Scientific coverage in water governance: systematic analysis. Water. 11 (1) 177. http://doi.org/10.3390/w11010177

FRANKS T and CLEAVER F (2007) Water governance and poverty: A framework for analysis. Prog. Dev. Stud. 7 (4) 291-306. https://doi. org/10.1177/146499340700700402
GWP (Global Water Partnership) (2002) Introducing effective water governance. GWP Technical Paper; 2002. Global Water Partnership, Stockholm.

GREEN C (2007) Mapping the field: the landscapes of governance. Sustainable Water Management in the City of the Future (SWITCH) Project Report. 2007. URL: www.switchurbanwater. eu\%2Foutputs\%2Fpdfs\%2FW6-1_GEN_RPT_D6.1.1b_Mapping_ Landscapes_of_Governance.pdf\&usg=AOvVaw0VXXULZMWWw 3BPXyWHSWxD (Accessed 20 November 2020).

JACOBS-MATA I and MUKUYU P (2020) Knowledge review and agenda setting for future investments in research on water governance in South Africa. WRC Report No. 2911/1/20. Water Research Commission, Pretoria. ISBN 978-0-6392-0129-0.

KJELLÉN M, TROPP H and JIMINEZ A (2015) Water governance in perspective - Water Governance Facility 10 years 2005-2015. SIWI, Stockholm.URL:https://www.watergovernance.org/resources/watergovernance-in-perspective/ (Accessed 15 November 2020).

LAUTZE J, DE SILVA S, GIORDANO M and SANFORD L (2011) Putting the cart before the horse: Water governance and IWRM. Nat. Resour. Forum. 35 (1) 1-8. https://doi.org/10.1111/j.1477-8947. 2010.01339.x

LOTKA, A (1926) The frequency distribution of scientific productivity. J. Wash. Acad. Sci. 16 (12) 317-324.

MCGINITY R and SALOKANGAS M (2014) Introduction: 'embedded research' as an approach into academia for emerging researchers. Manage.Educ. 28 (1) 3-5. https://doi.org/10.1177/0892020613508863

MINGERS J and LEYDESDORFF LA (2015). Review of theory and practice in scientometrics. Eur. J. Oper. Res. 246 (1) 1-19.

MOENCH M, DIXIT A, JANAKARAJAN $M$, RATHORE $S$ and MUDRAKARTHA S (2003) The fluid mosaic, water governance in the context of variability, uncertainty and change. A synthesis paper. Nepal Water Conservation Foundation, Kathmandu, and the Institute for Social and Environmental Transition. URL: https:// www.i-s-e-t.org/publications-and-resources-1/the-fluid-mosaic\%3Awater-governance-in-the-context-of-variability\%2C-uncertaintyand-change (Accessed 25 November 2020).

OLAGUNJU A, THONDHLANA G, CHILIMA JS, SÈNE-HARPER A, COMPAORÉ WN and OHIOZEBAU E, (2019) Water governance research in Africa: progress, challenges and an agenda for research and action. Water Int. 44 (4) 382-407.

OECD (Organisation for Economic Co-Operation and Development) (2011) Water governance in OECD countries: a multi-level approach. OECD Studies on Water. OECD Publishing, Paris. https://doi. org/10.1787/9789264119284-en

OECD (Organisation for Economic Co-Operation and Development) (2015) OECD Principles on Water Governance. Adopted by the OECD Regional Development Policy Committee on 11 May 2015, Paris.

ÖZEROL G, VINKE-DE KRUIJF J, BRISBOIS MC, FLORES CC, DEEKSHIT P, GIRARD C, KNIEPER C, MIRNEZAMI SJ, ORTEGA-REIG M, RANJAN P and SCHRÖDER NJ (2018) Comparative studies of water governance. Ecol. Soc. 23 (4). https:// doi.org/10.5751/ES-10548-230443

POURIS A (2017) The influence of collaboration in research priorities: The SADC Case. S. Afr. J. Sci. 113 (11-12) 1-3.

RHODES RAW (1996). The new governance: governing without government. Polit. Stud. 44 (4) 652-667. https://doi.org/10.1111/ j.1467-9248.1996.tb01747.x

ROGERS P and HALL A (2003) Effective water governance. TEC Background Paper 7: Global Water Partnership, Stockholm. URL: https://www.gwp.org/globalassets/global/toolbox/publications/back ground-papers/07-effective-water-governance-2003-english.pdf (Accessed 17 January 2021).

SERENKO A (2013) Meta-analysis of scientometric research of knowledge management: discovering the identity of the discipline. J. Knowl. Manage. 17 (5) 773-812. https://doi.org/10.1108/jkm-052013-0166

SIEBRITS R, WINTER K and JACOBS I (2014). Water research paradigm shifts in South Africa. S. Afr. J. Sci. 110 (5/6) 1-9.

TEMPELHOFF JW (2018) South Africa's Water Governance Hydraulic Mission (1912-2008) in a WEF Nexus Context. AOSIS, Cape Town. i626 pp. URL: https://books.aosis.co.za/index.php/ob/catalog/book/ 75 
WGF (UNDP Water Governance Facility at SIWI) (2020) What Is water governance? Water Governance Facility. URL: https://www. watergovernance.org/governance/what-is-water-governance/ (Accessed 18 January 2021).

WGF (UNDP Water Governance Facility at SIWI) (2016) Water Governance Issue Sheet. UNDP-SIWI Water Governance Facility. Stockholm International Water Institute (SIWI). https://www.water governance.org/wp-content/uploads/2016/08/Issue-sheet-Water-Gov ernance-WEB-1.pdf (Accessed 17 January 2021).

VAN KOPPEN B and SCHREINER B (2018) A hybrid approach to decolonize formal water law in Africa. IWMI Research Report 173. International Water Management Institute (IWMI). Colombo, Sri Lanka. 45 pp. https://doi.org/10.5337/2018.219

WEAVER MJT, O'KEEFFE JH, HAMER N and PALMER CG (2017) Water service delivery challenges in a small South African Municipality: Identifying and exploring key elements and relationships in a complex social-ecological system. Water SA. 43 (3) 398-408.
WOLFF MG, COCKBURN JJ, DE WET C, BEZERRA JC, WEAVER MJT, FINCA A, DE VOS A, RALEKHETLA MM, LIBALA N, MKABILE QB and co-authors (2019) Exploring and expanding transdisciplinary research for sustainable and just natural resource management. Ecol. Soc. 24 (4) 14. https://doi.org/10.5751/ES-11077240414

ZWARTEVEEN M, KEMERINK-SEYOUM JS, KOOY M, EVERS J, GUERRERO TA, BATUBARA B, BIZA A, BOAKYE-ANSAH A, FABER S, FLAMINI AC and co-authors (2017) Engaging with the politics of water governance: Opinion piece. Wiley Interdiscip. Rev.: Water. 4 (e1245) 